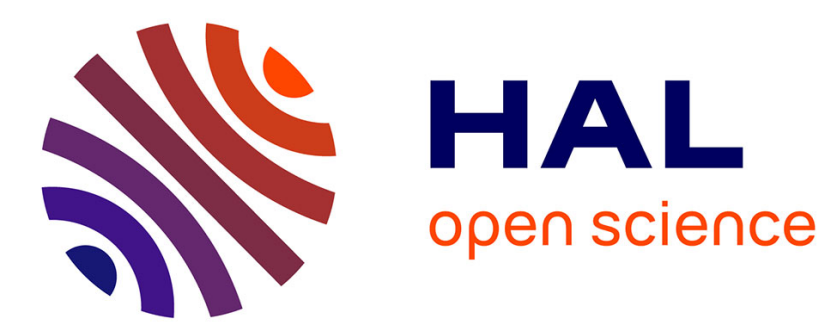

\title{
Considering sampling strategy and cross-section complexity for estimating the uncertainty of discharge measurements using the velocity-area method
}

\author{
A. Despax, C. Perret, R. Garçon, A. Hauet, A. Belleville, J. Le Coz, A.C.
}

Favre

\section{To cite this version:}

A. Despax, C. Perret, R. Garçon, A. Hauet, A. Belleville, et al.. Considering sampling strategy and cross-section complexity for estimating the uncertainty of discharge measurements using the velocityarea method. Journal of Hydrology, 2016, 533 (533), pp.128-140. 10.1016/j.jhydrol.2015.11.048 . hal-01728926

\section{HAL Id: hal-01728926 \\ https://hal.science/hal-01728926}

Submitted on 12 Mar 2018

HAL is a multi-disciplinary open access archive for the deposit and dissemination of scientific research documents, whether they are published or not. The documents may come from teaching and research institutions in France or abroad, or from public or private research centers.
L'archive ouverte pluridisciplinaire HAL, est destinée au dépôt et à la diffusion de documents scientifiques de niveau recherche, publiés ou non, émanant des établissements d'enseignement et de recherche français ou étrangers, des laboratoires publics ou privés. 


\section{Considering sampling strategy and cross-section complexity for estimating the uncertainty of discharge measurements using the velocity-area method.}

Aurélien DESPAX ${ }^{\mathrm{a}, \mathrm{b}, *}$, Christian PERRET ${ }^{\mathrm{a}}$, Rémy GARÇON ${ }^{\mathrm{a}}$, Alexandre HAUET $^{\mathrm{a}}$, Arnaud BELLEVILLE ${ }^{a}$, Jérôme LE COZc ${ }^{\mathrm{a}}$, Anne-Catherine FAVRE $^{\mathrm{b}}$

${ }^{a}$ EDF-DTG, 21 Avenue de l'Europe, BP 41, F-38040 Grenoble, France

${ }^{b}$ Univ. Grenoble Alpes, LTHE, F-38000 Grenoble, France

${ }^{c}$ Irstea, UR HHLY, Hydrology-Hydraulics, 5 rue de la Doua F-69626 Villeurbanne, France

\section{Abstract}

Streamflow time series provide baseline data for many hydrological investigations. Errors in the data mainly occur through uncertainty in gauging (measurement uncertainty) and uncertainty in the determination of the stage-discharge relationship based on gaugings (rating curve uncertainty). As the velocity-area method is the measurement technique typically used for gaugings, it is fundamental to estimate its level of uncertainty. Different methods are available in the literature (ISO 748, Q+, IVE), all with their own limitations and drawbacks. Among the terms forming the combined relative uncertainty in measured discharge, the uncertainty component relating to the limited number of verticals often includes a large part of the relative uncertainty. It should therefore be estimated carefully. In ISO 748 standard, proposed values of this uncertainty component only depend on the

\footnotetext{
*Corresponding author. Tel. : +33686 639831

Email address: aurelien.despax@ujf-grenoble.fr (Aurélien DESPAX)
} 
number of verticals without considering their distribution with respect to the depth and velocity cross-sectional profiles. The $Q+$ method is sensitive to a user-defined parameter while it is questionable whether the IVE method is applicable to stream-gaugings performed with a limited number of verticals. To address the limitations of existing methods, this paper presents a new methodology, called FLow Analog UnceRtainty Estimation (FLAURE), to estimate the uncertainty component relating to the limited number of verticals. High-resolution reference gaugings (with 31 and more verticals) are used to assess the uncertainty component through a statistical analysis. Instead of subsampling purely randomly the verticals of these reference stream-gaugings, a subsampling method is developed in a way that mimicks the behaviour of a hydrometric technician. A sampling quality index (SQI) is suggested and appears to be a more explanatory variable than the number of verticals. This index takes into account the spacing between verticals and the variation of unit flow between two verticals. To compute the uncertainty component for any routine gauging, the four most similar gaugings among the reference stream-gaugings dataset are selected using an analog approach, where analogy includes both riverbed shape and flow distribution complexity. This new method was applied to 3185 stream-gaugings with various flow conditions and compared with the other methods (ISO 748, IVE, $Q+$ with a simple automated parametrization). Results show that FLAURE is overall consistent with the $Q+$ method but not with ISO 748 and IVE methods, which produce clearly overestimated uncertainties for discharge measurements with less than 15 verticals. The FLAURE approach therefore appears to be a consistent method. An advantage is the explicit link made 
between the estimation of cross-sectional interpolation errors and the study of high-resolution reference gaugings.

Keywords: Discharge measurement, Uncertainty, Stream-gauging, Velocity-area method, Hydrometric data, River cross-section

\section{Introduction}

Hydrometric data are essential for many hydrological issues such as calibration of hydrological models, flood forecasting and warning (using hydrological modeling), engineering design (of dam or dyke for example) and policy decisions related to water resource management. For day-to-day power production operations including safety issues and water resource management, the Division Technique Générale (DTG) of Électricité de France (EDF) operates a hydrometric network. It includes about 300 hydrometric stations mainly spread on the mountainous regions of France (Alps, Pyrénées and Massif Central).

With such important issues, data quality must be ensured and at least evaluated. Some authors have investigated the sources of errors in discharge river measurement (McMillan et al., 2012) but, to date, uncertainty estimation is rarely associated with streamflow data.

Commonly, the streamflow records are based on continuous water level measurements converted by a stage-discharge relationship (called rating curve). Stream-gaugings at many different levels of flow are needed to plot a rating curve and to check the stability of the channel controls. For instance, in case of erosion or deposition processes, the channel of the stream may induce a change and a new rating curve has to be developed. 
Stream-gaugings have several functions such as the regulatory supervision (e.g. controlling minimum instream flow), the construction of the stagedischarge relationship and the rating curve validation (in case of geometric instability of the channel).

To meet all these functions, stream discharge measurements are not complete if the associated uncertainty is not provided. Uncertainties in streamgaugings should then be propagated for estimating the uncertainty associated with stage discharge relationships (Petersen-Øverleir and Reitan, 2009, McMillan et al., 2010, Morlot et al., 2014, Le Coz et al., 2014). In hydrometry a confidence level of $95 \%$ for uncertainty intervals is typically used (assuming a normal distribution for uncertainty) (see the Hydrometric Uncertainty Guidance: ISO, 2007b). The main difficulty in estimating uncertainty lies in the lack of streamflow reference data and in the natural time and space variability of river flows and beds.

The two main gauging techniques are the exploration of the velocity field by Doppler profilers (ADCP) or by the velocity-area method using currentmeters (WMO, 2010) and the tracer dilution (not discussed in the paper). The river discharge, $Q$, is estimated by integrating the normal flow velocities, $v$, and depths through the area $A$ of a cross-section (Herschy, 1993) according to Eq. (1) as follows:

$$
Q=\int_{A} v \mathrm{dA}
$$

Incomplete methods such as surface velocity measurement using hand- 
held Surface Velocity Radar (SVR) (Corato et al., 2011), Large-Scale Particle Image Velocimetry (LSPIV) (Hauet et al., 2008) or floats can also be applied to measure river discharge during floods. In such cases the field velocity is only explored in a partial way.

Although the ADCP technique is expanding rapidly, a significant proportion of the discharge measurements are still performed using the velocity-area method with a current-meter (in 2013, about 30\% of EDF-DTG measurements).

The velocity field is sampled using a number $m$ of verticals distributed across the river, where the vertical velocity profile is sampled by a current-meter at $n_{i}$ different depths.

Velocity measurements are performed with mechanical, electromagnetic or acoustic Doppler current-meters. The mid-section method is often used by hydrological services to compute discharge $Q$ as:

$$
Q=\sum_{i=1}^{m} Q_{i}=Q_{0}+Q_{m+1}+\sum_{i=1}^{m} B_{i} D_{i} V_{i}
$$

where $Q_{i}, B_{i}$ and $D_{i}$ denote the discharges, widths and depths of each subsection (or panel) $i$ respectively. $V_{i}$ are the mean normal-to-section velocities computed by integrating the vertical velocity profile. $Q_{0}$ and $Q_{m+1}$ correspond to partial discharges near each bank where the subsection velocity is determined by extrapolation. The alternative mean-section approach is not discussed in this study, since it does not produce significant differences in discharge computations.

There are a lot of sources of uncertainties in gaugings (e.g. Carter and Anderson, 1963, Pelletier, 1988, Sauer and Meyer, 1992) but the uncertainty 
of the velocity-area method heavily depends on the strategy of point measurement sampling and especially on the number $m$ and positions of verticals used to best describe the cross-section complexity.

Most of the computed uncertainty usually stems from the term $u_{m}$, due to the limited number of verticals (Le Coz et al., 2012). It must therefore be correctly computed. To address the limitations of existing uncertainty estimation methods (see section 2), this paper presents a new methodology, called FLow Analog UnceRtainty Estimation (FLAURE), to estimate the $u_{m}$ uncertainty component. A set of high-resolution gaugings (presented in section 3.1) is subsampled (section 3.2). Realistic stream-gaugings with any given number of verticals are produced (section 3.2) and lead to a new estimation of $u_{m}$ component depending on a sampling quality index (section 3.4). In order to take into account cross-sectional complexity, the $u_{m}$ component is estimated with the four most similar stream-gaugings selected among reference measurements (section 3.5). To evaluate the new uncertainty methodology (FLAURE) and compare it with ISO $748, Q+$ and IVE methods, uncertainties are computed using a set of 3185 routine streamgaugings (see section 4.2). A focus on three test cases is also presented in section 4.3. Section 5 summarizes the conclusions and perspectives of this work. 


\section{Overview of uncertainty estimation methods}

\subsection{General guidelines for sampling the cross-section}

It is hard to establish universal rules concerning the spacing between verticals and between points along each vertical. In France, these choices are left to the hydrometric technician considering his expertise and regarding bed geometry and flow distribution. During flood conditions it is advisable to reduce the number of point measurements due to potential flow variations and particularly for safety reasons. In all possible measuring situations these choices should lead to the most accurate and the most cost-efficient representation of reality. Some hydrometric technicians recommend that verticals should be regularly spaced but their positions should preferably depend on the transverse variation in bed geometry and flow distribution. Their positions should minimize the partial discharge, which means that more verticals must be placed where flow is higher (ISO, 2009, recommends that each $Q_{i}$ should not exceed $10 \%$ of the total discharge). The more the space between verticals is, the more the relative importance of a vertical in total flow is increased.

It is also judicious to place verticals as close as possible to the edges in order to minimize extrapolation and riverbank coefficients effects.

Various requirements can be found in ISO 748 standard (ISO, 2009) or other guidelines (e.g. Herschy, 1993, Forray et al., 1998, WMO, 2010). These general rules are applied in internal operating procedures by EDF-DTG hydrometric service.

It is very important to notice here that all these requirements must be 
followed. The estimation of uncertainty does not take into account error detection during measurement process. It is also assumed that all calibration corrections have been applied.

\section{2. $I S O 748$ standard}

To date, the method presented in the $I S O 748$ standard, which follows the Guide to the expression of Uncertainty in Measurement (GUM) (JCGM, 2008), is the framework for estimating uncertainty in velocity-area discharge measurements. Several assumptions are necessary for the implementation of these standards. For instance, it is assumed that the measurement errors follow a Gaussian (or at least unimodal) distribution.

The equation for the combined relative uncertainty in measured discharge $u(Q)$, at $68 \%$ level of confidence, proposed by the ISO 748 standard (ISO, 2009) is expressed as:

$$
u^{2}(Q)=u_{s}^{2}+u_{m}^{2}+\frac{\sum_{i=1}^{m} Q_{i}^{2}\left[u^{2}\left(B_{i}\right)+u^{2}\left(D_{i}\right)+u_{p}^{2}\left(V_{i}\right)+\frac{1}{n_{i}}\left\{u_{c}^{2}\left(V_{i}\right)+u_{e}^{2}\left(V_{i}\right)\right\}\right]}{\left(\sum_{i=1}^{m} Q_{i}\right)^{2}}
$$

The final expanded uncertainty $U$ is the combined relative uncertainty multiplied by a coverage factor $k=2$ to give the estimate for a $95 \%$ confidence interval as recommended by the Hydrometric Uncertainty Guidance (ISO, 2007b). Thereafter $U$ refers to the final expanded uncertainty while uncertainty components $u(X)$ indicate relative standard uncertainties (in \% of measurand $X$ ) at $68 \%$ confidence level. 
Uncertainty components $u(X)$ arise from several error sources due to:

- $u_{s}$ : residual systematic error after calibration of velocity, width and depth measuring devices,

- $u_{m}$ : limited number $m$ of verticals (transverse integration of unit flow $\left.q_{i}\right)$,

- $u\left(B_{i}\right)$ and $u\left(D_{i}\right)$ : random errors in width and depth measurements, respectively,

- $u_{p}\left(V_{i}\right)$ : limited number $n_{i}$ of point velocity measurements over vertical $i$,

- $u_{c}\left(V_{i}\right)$ : current-meter random errors,

- $u_{e}\left(V_{i}\right)$ : limited time of exposure for averaging turbulent velocity fluctuations.

The $u_{m}$ term accounts for on average $84 \%$ of the final expanded uncertainties computed on the EDF-DTG database. That is why particular attention should be paid to quantify this term. The major drawback of $\mathrm{ISO} 748$ method is the estimation of the uncertainty component $u_{m}$ related to the limited number $m$ of verticals. This component is determined by a table shown in Appendix E of ISO 748 standard (ISO, 2009) and depends only on the number $m$ of verticals. Their spatial distribution, the complexity of the riverbed shape and flow distribution are not taken into account. These empirical values are based on non-traceable experiments while most of the computed uncertainty stems from this component. 


\section{3. $Q+$ method}

The other limitations of ISO 748 method are well described by Le Coz et al. $(2012,2015 b)$ who developed an alternative methodology (named $Q_{+}$ method) for computing the relative standard uncertainty terms $u_{p}\left(V_{i}\right)$ and $u_{m}$. The equation issued from the $Q+$ method is expressed as:

$u^{2}(Q)=u_{s}^{2}+\frac{\sum_{i=0}^{m+1} Q_{i}^{2}\left\{u^{2}\left(B_{i}\right)+u^{2}\left(D_{i}\right)+u_{p}^{2}\left(V_{i}\right)+u_{m}^{2}\left(D_{i}\right)+u_{m}^{2}\left(V_{i}\right)+\frac{u_{c, e}^{2}\left(V_{i}\right)}{n_{i}}\right\}}{\left(\sum_{i=1}^{m} Q_{i}\right)^{2}}$

The $u_{p}\left(V_{i}\right)$ term, linked to the vertical integration of velocities, takes into account spacing between velocity points and discharge extrapolations in the top and bottom layers. Le Coz et al. (2012, 2015b) suggested dividing $u_{m}$ into uncertainties due to transverse integration of depths $u_{m}\left(D_{i}\right)$ and averaged velocities $u_{m}\left(V_{i}\right)$ while including discharge extrapolations to the edges. To compute these terms, the authors defined an angle $\alpha$ as the maximum transverse slope in order to quantify riverbed irregularity. This method improves ISO 748 method but is limited by the difficulty of choosing the value of $\alpha$ which has a large influence on the final uncertainty. A specific value of $\alpha$ should be used for each single gauging but this value is difficult to choose in practice. Instead of setting an arbitrary value of $\alpha$, for the study shown in this paper we compute this value for each stream-gauging as follows:

$$
\alpha=\frac{\sum_{i=1}^{m} Q_{i}\left|\alpha_{i}\right|}{Q}
$$


where $\alpha_{i}$ is the mean slope (expressed in degrees) of each subsection:

$$
\alpha_{i}=\frac{180}{2 \pi}\left\{\arctan \left|\frac{H_{i}-H_{i-1}}{x_{i}-x_{i-1}}\right|+\arctan \left|\frac{H_{i}-H_{i+1}}{x_{i}-x_{i+1}}\right|\right\}
$$

where $H_{i}$ and $x_{i}$ denote the elevation and the position of each vertical $i$, respectively.

\subsection{Interpolation Variance Estimator (IVE) method}

Another approach called Interpolated Variance Estimator (IVE) was developed and investigated by Kiang et al. (2009) and Cohn et al. (2013). The combined relative uncertainty is expressed as:

$$
u^{2}(Q)=u_{s}^{2}+\frac{\sum_{i=1}^{m} Q_{i}^{2}\left\{u^{2}\left(B_{i}\right)+u_{I V E}^{2}\left(D_{i}\right)+u_{I V E}^{2}\left(V_{i}\right)\right\}}{\left(\sum_{i=1}^{m} Q_{i}\right)^{2}}
$$

where

$$
\begin{gathered}
u_{I V E}\left(D_{i}\right)=\frac{\sqrt{\frac{1}{m-5} \sum_{i=3}^{m-2} \frac{\Delta_{i, D}^{2}}{2\left(1-\omega_{i}+\omega_{i}^{2}\right)}}}{\frac{1}{m-4} \sum_{i=3}^{m-2} D_{i}} \\
\Delta_{i, D}=D_{i}-D_{i, e s t} \\
D_{i, e s t}=\omega_{i} D_{i-1}+\left(1-\omega_{i}\right) D_{i+1} \\
\omega_{i}=\frac{x_{i+1}-x_{i}}{x_{i+1}-x_{i-1}}
\end{gathered}
$$


The Eq. 8 is based on statistical considerations. Larger departures from linearity in the measured profiles, expressed by Eq. 9, reflect larger uncertainties. The IVE method estimates separately the deviation of depth and velocity measurements from the linear interpolation of adjacent measurements according to Eq. 10. For $u_{I V E}\left(V_{i}\right)$ term, the same calculation is made by replacing $D_{i}$ with $V_{i}$ in Eq. 8, 9 and 10. However, it is unclear how departure from linearity can capture all the sources of error on depth or velocity $\left(u_{p}\left(V_{i}\right), u_{c}\left(V_{i}\right)\right.$ and $u_{e}\left(V_{i}\right)$ for instance). Moreover, this assumption may be false when few verticals are made.

According to Eq. (7), the components of uncertainty $u_{p}\left(V_{i}\right), u_{c}\left(V_{i}\right), u_{e}\left(V_{i}\right)$ and $u\left(D_{i}\right)$ are supposed to be included in $u_{I V E}\left(V_{i}\right)$ and $u_{I V E}\left(D_{i}\right)$. Consequently the IVE method does not allow the computation of the contribution of each error source and does not provide insight into strategies that might be applied to reduce the final uncertainty. Furthermore, errors due to extrapolation are not taken into account since the index varies between $i=3$ and $i=m-2$.

\subsection{Towards a new approach}

The $I S O$ 748, Q+ and IVE methods presented above must be improved due to their limitations. They are not able to evaluate both the sampling strategy and the complexity of the cross-section. Therefore, we propose a new methodology to objectively estimate $u_{m}$, on the basis of the sampling strategy, the riverbed shape and the flow distribution complexity altogether.' 


\section{Methodology: Flow Analog UnceRtainty Estimation (FLAURE)}

The developed method, called FLow Analog UnceRtainty Estimation (FLAURE), proposes a new methodology to estimate the $u_{m}$ term which is the dominant term in the combined uncertainty. Other uncertainty components in $Q+$ method are considered satisfying.

The Buech stream-gauging at Serres hydrometric station is used here as an example.

The method presented below is based on 18 high-resolution stream-gaugings (named reference stream-gaugings) specifically performed for this study (section 3.1). It proceeds as follows:

1. The high-resolution measurements are subsampled by reducing the number of verticals to produce a sample of realistic stream-gaugings (section 3.2).

2. For each reference stream-gauging, the $u_{m}$ component is estimated through the comparison between subsampled gaugings and the initial reference gauging (section 3.3).

3. A sampling quality index is introduced and computed for each subsampled gauging (section 3.4).

These three steps lead to curves of $u_{m}$ component as a function of the sampling quality index, for each reference stream-gauging. The position of each curve depends on the complexity of the stream-gauging cross-section and flow. The following step allows the computation of the $u_{m}$ component of any routine stream-gauging. 
4. The $u_{m}$ component of any routine stream-gauging is based on uncertainty estimates provided by the four most similar stream-gaugings, named analogs, selected among the reference stream-gaugings (section 3.5). Finally, the $u_{m}$ term of any routine gauging is computed as a weighted sum including the four analogs and depends on the sampling quality index.

\subsection{Reference stream-gaugings dataset}

A set of 18 high-resolution gaugings (each based on a number of verticals between 31 and 83) with various site and flow conditions is used as reference gaugings. Characteristics of these gaugings are summarized in Table 1. We call these measurements "reference stream-gaugings" and assume that they encompass all possible cases such as rectangular man-made channel, small complex stream or wide river. 11 stream-gaugings were operated using 31 to 53 verticals. This type of measurement is very time-consuming so additional reference gaugings were derived from acoustic Doppler current profiler measurements.

Measurements were operated as follows:

- 11 stream-gaugings applying velocity-area method with mechanical and electromagnetic current-meters on a wading rod. At least 3 points by vertical and more than 30 verticals were used. Time of exposure for velocity-point measurement was set to 30 seconds.

- 7 stream-gaugings using acoustic Doppler current profiler (ADCP) converted into equivalent stream-gaugings made with a current-meter. To get one equivalent stream-gauging, several successive transects (at least 
6) measuring the same cross-section with an ADCP are used. Velocities are projected and averaged on a grid representing every point measurement. At each point, a velocity-point measurement is computed only if more than 30 ADCP velocity measurements are observed at the vicinity of each point of the grid. The average corresponds to an exposure time of 30 seconds, which is typical of our current-meter stream-gaugings.

We verified that no significant flow variation was observed during all those measurements.

\subsection{Subsampling method}

As previously stated, the major limitation of $I S O 748$ method lies in the estimation of the uncertainty component $u_{m}$. The ISO 1088 standard (ISO, 2007a) recommends: "To determine the influence of the distribution of horizontal velocity and depth between the verticals on the total uncertainty in discharge, it is necessary to make a detailed measurement of the cross-section [...]." Obviously, such measurements are not possible in practice because they are time-consuming. Moreover, the increase in the duration of measurement results in a higher risk of streamflow variation. Carter and Anderson (1963) and Herschy (1975) conducted this kind of approach by reducing the number of verticals (taking only a proportion of $1 / 2,1 / 4$ or $1 / 5$ for instance) but without taking into account the behavior of the hydrometric technician. Results of these studies were probably at the origin of mean values presented in ISO 748 standard. Accordingly, these results do not take into account the complexity of the cross-section and this method is not recommended given the diversity of river cross-sections (Forray et al., 1998, Le Coz et al., 2012, 
$2015 b)$.

The subsampling method consists in generating several stream-gaugings with diverse spatial distribution of verticals while trying to simulate as well as possible the behavior of a hydrometric technician. For each number of verticals, 1000 stream-gaugings are generated and associated discharges are calculated.

Each high-resolution gauging of our reference dataset is subsampled by reducing the number of verticals. The subsampling method simulates the behavior of stream gaugers by a pseudo-random sampling procedure. It generates subsampled stream-gaugings with at least 5 verticals since the majority of EDF-DTG stream-gaugings are performed with 5 verticals or more $(5$ verticals correspond to the $1 \%$ percentile). Following general guidelines described in section 2.1, a probability is affected to vertical selection depending on:

- The proximity with a vertical already selected,

- the vicinity with the shore,

- the gain of information provided by the vertical.

According to internal operating procedures, in the first subsampling step the first and last verticals $(i=1$ and $i=m)$ are consistently chosen as close as possible to the limits of the section so as to minimize the influence of extrapolations. These $j=2$ first verticals are the same for all the subsampled gaugings. 
Probabilities of sampling verticals are then computed using the unit flow of initial stream-gauging (noted $q)$ defined as:

$$
q_{i}=D_{i} V_{i}
$$

where $i$ varies between 2 and $m-1$.

In case of a gauging using a few number of verticals, a hydrometric technician would select a vertical in the middle of the cross-section, where the velocity is higher and where the flow is the same on either side of the vertical. Thus, to choose a vertical distant to a vertical already selected and at the "center of gravity" of the flow distribution, a probability $P_{1, i}$ is affected depending on partial flows to the left $\left(Q_{i, \text { left }}\right)$ and to the right $\left(Q_{i \text {,right }}\right)$ (see Figure 1a) between vertical $i$ and closest verticals already selected as:

$$
P_{1, i}=\frac{\min \left(Q_{i, \text { left }}, Q_{i, \text { right }}\right)}{\sum_{i=1}^{m-j} \min \left(Q_{i, \text { left }}, Q_{i, \text { right }}\right)}
$$

$Q_{i, \text { left }}$ (respectively $Q_{i, \text { right }}$ ) denotes the integral of unit flow $(q)$ between vertical $i$ and its closest vertical on the left (respectively on the right). The index $j$ denotes the number of verticals already selected.

The probability will be maximized if partial flow on either side is the same (see Figure 1c). We notice that as required the sum of the probabilities is equal to 1 .

In computing a discharge measurement, the depth and the velocity are assumed to vary linearly with the distance between verticals. Consequently, an operator tends to select verticals where the changes of slope are high. 
Thus, another probability $P_{2, i}$ is computed to select a vertical for which the unit flow is very different to a linear interpolation between the verticals already selected (Eq. 14). The difference between the unit flow at vertical $i$ and the interpolation between verticals selected, separated by a distance of $L_{\mathrm{i}, \text { sep }}$, is noted $\Delta q_{i}$ (see Figure $\left.1 \mathrm{~b}\right)$.

$$
P_{2, i}=\frac{\Delta q_{i} L_{\mathrm{i}, \mathrm{sep}}}{\sum_{i=1}^{m-j}\left(\Delta q_{i} L_{\mathrm{i}, \mathrm{sep}}\right)}
$$

The probability $P_{2, i}$ allows to sample a vertical where the $q$ curve is very uneven while maintaining the separation distance in a homogeneous way (see Figure 1d).

In order to give equal importance to both probabilities, the final probability $P_{i}$ for selecting a vertical $i$ is computed as:

$$
P_{i}=\frac{P_{1, i}+P_{2, i}}{2}
$$

A vertical numbered $j$ is sampled randomly according to the probability distribution computed above (see Figure 1e). Probabilities are computed again and verticals are selected one by one while $m-j$ verticals are still available. When the number of sampled verticals $j$ is equal to the initial number of the reference stream-gauging $m$, the sampling process is completed. To produce various stream-gaugings, this process is iterated $k=1000$ times. For instance, 1000 different gaugings with 10 verticals are generated. 


\subsection{Uncertainty related to the number of verticals}

It is assumed that the true value of the discharge occurs when all the $m$ verticals of the reference stream-gauging are used $\left(Q_{m}\right)$. In practice, the true discharge is unknown but only the influence of the number of verticals has been taken into consideration in this study. Thus, the relative errors can be computed for each subsampled gaugings (stream-gauging number $k$ where $k=1, \cdots, 1000$ with $j$ verticals) as:

$$
E_{j, k}=\frac{Q_{j, k}-Q_{m}}{Q_{m}}
$$

Figure 2 shows the relative error depending on the number of verticals for the Buech river stream-gauging at Serres. As expected, the relative error is larger when the number of vertical decreases.

This figure highlights also a bias since the error distribution is not centered around 0 (for 10 verticals, the median value is $-0.62 \%$ ). The same analysis performed on the other reference stream-gaugings shows that the bias depends on the shape of the cross-section. It is observed that the bias is larger for the most complex cross-section. In practice the hydrometric technician chooses obviously a higher number of vertical to best describe such a complex cross-section. It is difficult to determine if the origin of the bias is the subsampling method (by construction) or the lack of verticals. In most cases, the bias is low (less than $1 \%$ in absolute value) and we assume that the operator is able to limit the bias while following all the requirements, i.e. by selecting point measurements as close as possible to the edges and by best describing lateral velocity and depth progressive gradient. 
In Figure 2, the $15 \%$ and $85 \%$ empirical percentiles can be compared with $u_{m}$ computed following ISO 748 standard since the distance between these two percentiles can be seen as a $70 \%$ empirical confidence interval. These percentiles show a slight asymmetry around the median value. The skewness can be estimated by the quartile skewness coefficient, also known as Bowley skewness (Bowley, 1920) defined by:

$$
S_{q}=\frac{\left(Q_{3}-Q_{2}\right)-\left(Q_{2}-Q_{1}\right)}{Q_{3}-Q_{1}}
$$

where $Q_{1}, Q_{2}$ and $Q_{3}$ denote the first, second and third quartiles, respectively.

If this coefficient is positive, the data are positively skewed or skewed right, implying that the discharge is more often overestimated. In most cases skewness is negative meaning that the discharge is often underestimated. As an example, $S_{q}$ is equal to -0.03 for 1000 subsampled stream-gaugings with 10 verticals from the Buech at Serres gauging and shows a slightly skewed left distribution. It can be explained by the global concave shape of the river cross-section. The depth and the velocity are assumed to vary linearly with distance between verticals in computing a discharge measurement which often leads to an underestimation of the true discharge (Eq. 1).

A distribution-free test (or nonparametric test) of symmetry has been performed using a bootstrap method (Davison and Hinkley, 1997) with 1000 replicates. For each number of verticals an empirical confidence interval of skewness (at a confidence level of $1-\alpha=95 \%$ ) is computed using the 2.5 and $97.5 \%$ empirical percentiles. When $S_{q}=0$ is included in the interval, the null hypothesis of the symmetry of the relative error distribution cannot be rejected (with $\alpha=5 \%$ ). In the majority of cases we observe that the 
confidence interval includes $S_{q}=0$. It can be thus deduced that the relative error distribution is not significantly skewed. However in order to take into account the small skewness, the estimation of the $u_{m}$ term is taken as the maximum between the $85 \%$ percentile minus the $50 \%$ percentile and the $50 \%$ percentile minus the $15 \%$ percentile:

$$
u_{m}=\max \left\{p_{85 \%}(m)-p_{50 \%}(m), p_{50 \%}(m)-p_{15 \%}(m)\right\}
$$

For each reference stream-gauging, $u_{m}$ is estimated and represented depending on the number of verticals in Figure 3. Since each reference streamgauging is distinctive, the number of verticals $m$ is not satisfactory enough to be explanatory. For 11 verticals which correspond to an usual gauging (see Table 2), $u_{m}$ ranges from $2 \%$ to $7.5 \%$. This figure illustrates that the use of the number of verticals in $I S O 748$ method for estimating the uncertainty is not appropriate considering the diversity of cross-sections in natural rivers. The relative error should depend both on the strategy adopted to select verticals and on the cross-section complexity.

\subsection{New computation of $u_{m}$ depending on a sampling quality index}

According to general guidelines, a good sampling can be obtained when spacing between verticals is quite homogeneous, variations between adjacent measurements are as minimal as possible and of the same order of magnitude. In this way and in order to evaluate the strategy for selecting verticals of each gauging, we define a sampling quality index $(S Q I)$ as: 


$$
S Q I=\frac{\sigma(\Delta q)}{\sigma(q)} \frac{\sum_{i=1}^{m}\left(\Delta x_{i} \Delta q_{i}\right)}{Q}
$$

This dimensionless criterion has the advantage to take into account:

- The spacing between verticals $\left(\Delta x_{i}\right)$ which will increase $S Q I$ if they are widely spaced,

- the variation of unit flow between two adjacent verticals $\left(\Delta q_{i}\right)$ which will also increase $S Q I$ if changes in flow distribution are not enough sampled,

- a ratio between the standard deviation of adjacent measurement $(\sigma(\Delta q))$ and the standard deviation of unit flow $(\sigma(q))$. The denominator of the ratio is quite stable (intrinsic variability of the cross-section) while the numerator must reduce when the number of verticals increases and variations between adjacent verticals are low.

A theoretical value of $S Q I=0$ means that the spacing between verticals is infinitesimally small. It implies that discharge is integrated according to Eq. 1. On the other hand, $S Q I$ shall reasonably not exceed a value of 1 . Although high differences between adjacent measurements and inappropriate spacing among verticals can be highlighted by $S Q I$, it does not allow error detection.

Figure 4 shows the relative error depending on the sampling quality index for the Buech stream-gauging at Serres. As mentioned above, the difference between the empirical $85 \%$ and $50 \%$ percentiles or the difference between the 
$50 \%$ and $15 \%$ percentiles is computed to estimate the $u_{m}$ term (see Eq. 18) depending on $S Q I$ (instead of $m$ ). A threshold of 100 values is required for estimating empirical percentiles. Then the $u_{m}$ term is smoothed using a local regression function and plotted for each reference stream-gauging depending on $S Q I$ in Figure 5. We set a minimum value of $1 \%$ for the $u_{m}$ term which is the same threshold of $u_{m}$ found in $I S O 748$ standard (ISO, 2009).

Figure 5a shows $u_{m}$ depending on the sampling quality index. In Figure 5b, three bathymetric profiles illustrate the level of complexity of the riverbed. We observe that all the curves converge. While the number $m$ of verticals does not take into account their spatial distribution, the $S Q I$ criterion allows to compare various stream-gaugings using the same consistent scale.

This figure shows that the position of curves depends only on the configuration of the bathymetric profile of the riverbed and also on the flow distribution. For instance, stream-gauging with a very uneven bathymetric profile and a complex flow distribution has a higher uncertainty compared to a rectangular open-channel.

\subsection{Selecting analog hydraulic conditions}

As mentioned above, the $u_{m}$ estimation depends on the complexity of the stream-gauging. Due to the natural space variability of river flows and beds, riverbed shape and flow distribution complexity altogether have to be taken into account for estimating the uncertainty related to any stream-gauging. Curves presented in section 3.4 are based on reference stream-gaugings. The uncertainty component $u_{m}$ of any routine stream-gauging should indeed be 
computed following results of gaugings with similar hydraulic conditions. For that purpose, cross-sectional complexity is considered by selecting analogs in the reference stream-gauging dataset.

This analogy is based on dimensionless lateral velocity distribution and dimensionless bathymetric profile which are concatenated to produce a signal. This signal is then compared with all reference stream-gaugings signals using the Nash (or NSE) criterion (Nash and Sutcliffe, 1970). Each stream-gauging is unique. Thus, it cannot be assumed that a stream-gauging is exactly the same as a reference stream-gauging. The four most similar stream-gaugings are thus selected.

Several similarity criteria such as KGE (Gupta et al., 2009), VE (Volumetric Efficiency) and Pearson correlation coefficient have been tried and tested. Nash criterion is both simple and robust to select adequate analogs. Only criteria with a value greater than 0 are considered to be relevant.

The $u_{m}$ term of any routine gauging is computed as a weighted sum including the four analogs, the weights being the corresponding Nash criterion as follows:

$$
u_{m}=\frac{\sum_{i=1}^{4} \operatorname{Nash}_{i} u_{m, i}}{\sum_{i=1}^{4} \operatorname{Nash}_{i}}
$$

A sensitivity analysis about the number of analogs shows that the computed uncertainty exhibits a small sensitivity. When more than 10 analogs are retained, results are too smoothed and information coming from the stream-gauging complexity is lost. Furthermore, the four most similar stream- 
gaugings present a good score and are more relevant compared with the others.

\section{Application of the new methodology}

ISO 748, Q+, IVE and the FLAURE methods are applied to the EDFDTG dataset and three test cases are presented to compare the four methods. We stress that the final expanded uncertainties are expressed at the $95 \%$ confidence level.

\subsection{EDF-DTG database}

3185 gaugings ranging from 0.01 to $864\left[\mathrm{~m}^{3} / \mathrm{s}\right]$ are used to compare $I S O 7_{4} 8, I V E$ and $Q+$ methods with the new methodology. These gaugings were extracted from EDF-DTG database and respect requirements found in ISO 748 standard and internal operating procedures. Statistical characteristics summarizing these gaugings are presented in Table 2. Measurements were made at 300 locations of EDF-DTG hydrometric network in France. The majority of stream-gaugings were operated in small moutains river (the order of magnitude of the width is on average 10 meters). On average, the number of verticals is around 10. Thus, discharges of each subsection can exceed $10 \%$ of the total flow which slightly deviates from the $I S O 748$ standard.

\subsection{Uncertainty computation to the database}

The four methods are applied to 3185 stream-gaugings (EDF-DTG database). The FLAURE method follows the procedure below: 
1. Computation of the sampling quality index $(S Q I)$ according to Eq. 19,

2. Analog selection (see section 3.5) and estimation of $u_{m}$ using Eq. 20 depending on $S Q I$ computed,

3. Replacing the $u_{m}$ term into Eq. $4(Q+$ method $)$ to deduce the final expanded uncertainty.

The vast majority of $S Q I$ values computed on EDF-DTG database ranges from 0.02 to 0.4 with a more frequent value equal to 0.1 as shown in Figure 6. Values of $S Q I$ over 0.5 reveals very complex cross-section and could sometimes highlight mistakes in data entry.

Less than $1 \%$ of the stream-gaugings have less than four selected analogs. It means that these stream-gaugings are distinctive. It also indicates that the 18 chosen reference stream-gaugings represent all the different types of cross-section in the dataset. In the case where no analogs can be found (the cross-section is very uncommon and uneven), the $u_{m}$ term is estimated using the maximum value of uncertainty associated to the sampling quality index computed (i.e. the worst case).

Figure 7 illustrates the final expanded uncertainty $U(Q)[\%]$ computed with the four methods. While ISO 748 standard strongly depends on the number of verticals, the three other methods produce more nuanced results. In terms of range of results, maximum values are obtained with the IVE method when the number of verticals is small. According to Eq. 8 and 9, the uncertainty is very sensitive when the variability of the riverbed is high 
(i.e. when $\Delta_{i, D}$ are high) which is often the case for small streams or mountainous rivers. On the other hand, for very smooth channels, when measured depths (respectively velocities) show almost linear or constant evolution, the method may underestimate the uncertainty. The IVE method leads to very high uncertainties. Thus, the method seems not suitable for discharge measurements made with a few number of verticals.

The new method produces more subtle results which are consistent with values expected by experts (Forray et al., 1998). A value of $15 \%$ is assigned for uneven gaugings while smoothed cross-sections could take a minimum value of around $3 \%$. Mean and median values are both equal to $5 \%$ and correspond to recommended value of uncertainty for good condition measurement.

Figure 8 illustrates the distribution of the final expanded uncertainty obtained with the four methods as histograms. The $Q+$ and FLAURE methods present similar histograms whereas IVE values are larger and exhibit more wider span. The median value of the $I V E$ approach is very high (more than $11 \%$ ) which highlights that the method seems not to be applicable to our dataset due to a relatively small number of verticals which is common practice at EDF-DTG. The method has indeed been developed for stream-gaugings with a number of verticals equal or greater than 20, which corresponds to requirements in the U.S. (Rantz et al., 1982).

Figure 9 confirms that ISO and IVE methods overestimate the uncertainty compared to the FLAURE approach. The computation of $\alpha$ proposed in Eq 5 leads to similar uncertainties between $Q+$ and FLAURE methods 
(see Figure 9c). Once again, Figure 9d illustrates the sensitivity of the $Q_{+}$ method to the value of $\alpha$. The results are very different with an arbitrary value of $\alpha=10$ degrees. This underlines the need to objectify the angle $\alpha$ while the FLAURE method does not require any subjective parameter to compute the uncertainty.

\subsection{Test cases}

Three different gaugings are selected to deeply discuss the results of the new method in comparison with the results of $I S O$ 748, Q+ and IVE methods: the Romanche at Champeau, the Souloise at Infernet and a subsampled gauging from the Buech at Serres. Figure 10 shows the lateral velocity distribution and the bathymetric profile of each gauging. The first case illustrates a very smooth cross-section while the second case has a uneven velocity distribution which should induce a high level of uncertainty. The third case demonstrates the robustness of the analogs selection method. Values of the final expanded uncertainty are shown in Table 3.

Case 1: the Romanche river discharge measurement at Champeau in 2010 with 8 verticals (see Figure 10a). This cross-section is quite wide with a width-to-depth ratio $\frac{B}{D} \approx 25$. The smooth and trapezoid cross-section is well represented by the selected analogs (Gaugings 1, 5, 4 and 9). Due to a smooth section only 8 verticals were used. As a consequence, most subdischarges are greater than $15 \%$ of total discharge but extrapolated edge discharges are negligible compared to total discharge. According to the limited number of verticals, this example measurement is not qualified as standard with respect to the $\mathrm{ISO} 748$ requirements. The uncertainty computed with $\mathrm{ISO}_{4} \mathrm{H}_{4} 8$ stan- 
dard leads to a high value of $11 \%$ since the number of vertical is low. Due to the large spacing between verticals number 2 and 3, the IVE method leads to a value of $14 \%$ although lateral gradients of depth and velocity are small. Following Eq. 5, $\alpha=3^{\circ}$ and the final uncertainty computed with the $Q_{+}$ method is $4.6 \%$. In the case of the FLAURE approach the variability of the unit flow is very low which leads to a small value of $S Q I$ and an expanded uncertainty of $4 \%$ which correspond to an usual value of uncertainty given the smooth cross-section and velocity profiles. FLAURE and $Q+$ methods produce the similar results but the $Q+\operatorname{method}$ is sensitive to angle $\alpha$. For instance, a value of $\alpha=10^{\circ}$ leads to a value of $12.5 \%$ given the spacing between verticals number 2 and 3 .

Case 2: The Souloise river at Infernet gauging station in 2011 with 14 verticals (see Figure 10b). This gauging is typical of low flow conditions in a small mountainous river with a width-to-depth ratio $\frac{B}{D} \approx 13.14$ verticals were distributed throughout the cross-section to better capture lateral velocity variability. Since the bathymetric profile is quite smooth, a value of $\alpha=8^{\circ}$ is computed for $Q+$. The relatively high number of verticals leads to moderate values of uncertainty for $I S O 748$ and $Q+$ methods (with $7 \%$ and $4 \%$ respectively) despite of the fact that lateral velocity profile is uneven. On the other hand, the IVE method is too sensitive to the high variability of velocity profile with an expanded uncertainty of more than $30 \%$. The FLAURE method leads to a reasonable value of $10 \%$. Selected analogs correspond to uneven and shallow river cross-sections. 
Case 3: This gauging $\left(Q=2.75\left[\mathrm{~m}^{3} / \mathrm{s}\right]\right.$, see Figure $\left.10 \mathrm{c}\right)$ is a subsampled gauging from the Buech river at Serres reference stream-gauging with initial discharge of $2.81\left[\mathrm{~m}^{3} / \mathrm{s}\right]$ considered here as the true value. The subsampled gauging can be seen as a typical measurement while the original one gives the best estimation of the discharge. The relative error between these gaugings is equal to $2 \%$. An uncertainty of around $4 \%$ is obtained using $Q+$ method (with a value of $\alpha=3$ degrees) and $5 \%$ for the FLAURE method. We notice here that the $Q+$ method is very sensitive to the angle $\alpha$ : expanded uncertainties fluctuate between $5 \%$ and $16 \%$ for values of $\alpha$ ranging from 5 to 20 degrees. ISO 748 computation leads to a value of around $9 \%$ while IVE method gives $11 \%$.

The best selected analog is as expected the initial Serres gauging with a Nash criterion of 0.97 while the second analog is Voiron (Morge river) with a Nash criterion of 0.62 . This example shows that the Nash criterion used for selecting analogs is quite robust.

\section{Conclusions}

An alternative method to estimate the cross-sectional interpolation errors is proposed in this paper. It improves the estimation of $u_{m}$ and leads to consistent values of uncertainty with $Q+\operatorname{method}$. It seems to be adequate for various cross-sectional configurations including complex cross-sections and smooth man-made channels. The approach makes it possible to better take into account both the sampling strategy quality and the complexity of the cross-section. Uncertainty, especially the $u_{m}$ term, is estimated using only data belonging to the stream discharge measurement. No subjective parame- 
ter or additional measurement are needed. Thus, the approach is suitable for any historical or future stream-gauging. It has also been demonstrated that the simple computation of $\alpha$ in the $Q+$ method proposed in this study leads to similar results than the FLAURE method. Although the $Q+$ method is simpler, the FLAURE approach refers to explicit reference gaugings taken as analog cases. Using an analog approach, values of the $u_{m}$ term are based on 18 very detailed measurements made in the field. These measurements were conducted in various flow conditions and from cross-sections with different morphologies. This database seems to be sufficient for assessing the uncertainty of most common gaugings operated by EDF-DTG in France (quite small rivers). For very unusual cross-sections (less than 1\% of EDF-DTG dataset), no analogs are found. In such cases the maximum value of the $u_{m}$ term is affected according to its sampling quality index. The weak point of this part of the approach may be the diversity of reference stream-gaugings. However, we think that the maximum value can reasonably be used when no analog is found since the cross-section is probably very uneven or the lateral distribution of flow is unusual. It is therefore of interest to complete the reference database with unusual stream-gauging and gaugings operated by other organizations throughout the world. Such a database could also be interesting for estimating uncertainty in steamflow measurements using acoustic profilers (ADCP).

In addition, the original subsampling method produces realistic stream-gaugings and is in line with the behavior of a hydrometric technician. Consequently, the estimation of $u_{m}$ is consistent. 
Another limitation is that the systematic errors remains difficult to estimate. The bias of the stream-gauging technique is hard to quantify since river discharge references are rarely available and usually themselves too uncertain. Other factors influencing the operators, such as stress, lack of time and weather conditions are not taken into account although it could include a significant part of the uncertainty. The uncertainty related to operator skill is not quantified. Although the sampling quality index $(S Q I)$ is easy to compute and could be used in the field as an indicator to improve the strategy of selecting point measurements while the operator is gauging; we remind that all the requirements in ISO 748 standard (ISO, 2009) or other guidelines (Forray et al., 1998, WMO, 2010) must be followed in order to avoid errors.

Further research is needed to validate the method. For instance, sensitivity tests would provide information on the robustness of the results with respect to the number of reference stream-gaugings. It would also be interesting to apply the four methods to a stream-gauging dataset coming from other hydrometric services with other procedures, other types of sites and different flow conditions. It could be interesting to compare methods based on the GUM framework with methods based on other mathematical tools such as grey numbers (Alvisi et al., 2014) and fuzzy logic (Shrestha and Simonovic, 2010) for assessing the uncertainty in discharge measurement. Comparison between field interlaboratory experiments (Blanquart, 2013, Le Coz et al., 2015a) and uncertainty propagation methods which are based on the GUM approach (i.e. ISO 748 standard; IVE, $Q+$ and FLAURE methods) will also 
make it possible to highlight the best approach and improve them.

\section{Acknowledgments}

The authors are grateful to J. Kiang for sharing her codes and for her active collaboration. EDF-DTG which supports this study is gratefully acknowledged, especially the whole hydrometric team, D. Sevrez, F. Gottardi, T. Mathevet, J. Gailhard, T. Morlot, P. Vignon and J.P. Escallon. We also thank the two reviewers and the editor for their helpful comments on the manuscript. 


\section{Reference}

Alvisi, S., Barbetta, S., Franchini, M., Melone, F., and Moramarco, T. (2014). Comparing grey formulations of the velocity-area method and entropy method for discharge estimation with uncertainty. Journal of Hydroinformatics, 16(4):797-811.

Blanquart, B. (2013). Panorama des méthodes d'estimation des incertitudes de mesure. (In French) [Overview of the methods for estimating measurement uncertainties]. La Houille Blanche, 6:9-15.

Bowley, A. L. (1920). Elements of statistics, volume 2. PS King.

Carter, R. W. and Anderson, I. E. (1963). Accuracy of current meter measurements. Journal of the Hydraulics Division, 4(1):105-115.

Cohn, T., Kiang, J., and Mason, R. (2013). Estimating discharge measurement uncertainty using the interpolated variance estimator. Journal of Hydraulic Engineering, 139(5):502-510.

Corato, G., Moramarco, T., and Tucciarelli, T. (2011). Discharge estimation combining flow routing and occasional measurements of velocity. Hydrology and Earth System Sciences, 15(9):2979-2994.

Davison, A. C. and Hinkley, D. V. (1997). Bootstrap methods and their application, volume 1. Cambridge university press.

Forray, N., Auer, J. C., Brochot, J. F., Eraud, Y., Favriau, A., Ghio, M., Lallement, C., Lang, M., Odier, M., and Scherer, C. (1998). Charte qualité 
de l'hydrométrie. Code de bonnes pratiques. (In French) [Quality charter for hydrometry].

Gupta, H. V., Kling, H., Yilmaz, K. K., and Martinez, G. F. (2009). Decomposition of the mean squared error and NSE performance criteria: Implications for improving hydrological modelling. Journal of Hydrology, $377(1-2): 80-91$.

Hauet, A., Kruger, A., Krajewski, W., Bradley, A., Muste, M., Creutin, J. D., and Wilson, M. (2008). Experimental System for Real-Time Discharge Estimation Using an Image-Based Method. Journal of Hydrologic Engineering, 13(2):105-110.

Herschy, R. W. (1975). The accuracy of existing and new methods of river gauging. PhD thesis, University of Reading.

Herschy, R. W. (1993). The velocity-area method. Flow Measurement and Instrumentation, 4(1):7-10.

ISO (2007a). ISO 1088:2007 - Hydrometry - Velocity-area methods using current-meters Collection and processing of data for determination of uncertainties in flow measurement.

ISO (2007b). ISO/TS 25377:2007 - Hydrometry - Hydrometric Uncertainty Guidance (HUG).

ISO (2009). ISO 748:2009 - Hydrometry - measurement of liquid flow in open channels using current-meters or floats. 
JCGM (2008). Evaluation of measurement data - Guide to the expression of uncertainty in measurement. Guide 100, BIPM.

Kiang, J., Cohn, T., and Mason, R. (2009). Quantifying uncertainty in discharge measurements: A new approach. In World Environmental and Water Resources Congress 2009, pages 1-8. American Society of Civil Engineers.

Le Coz, J., Blanquart, B., Pobanz, K., Dramais, G., Pierrefeu, G., Hauet, A., and Despax, A. (2015a). Estimating the uncertainty of streamgauging techniques using field interlaboratory experiments. Journal of Hydraulic Engineering (in press).

Le Coz, J., Camenen, B., Peyrard, X., and Dramais, G. (2012). Uncertainty in open-channel discharges measured with the velocity-area method. Flow Measurement and Instrumentation, 26:18-29.

Le Coz, J., Camenen, B., Peyrard, X., and Dramais, G. (2015b). Erratum to "Uncertainty in open-channel discharges measured with the velocityarea method [flow measurement and instrumentation 26 (2012) 18-29]. (in press)". Flow Measurement and Instrumentation.

Le Coz, J., Renard, B., Bonnifait, L., Branger, F., and Le Boursicaud, R. (2014). Combining hydraulic knowledge and uncertain gaugings in the estimation of hydrometric rating curves: A Bayesian approach. Journal of Hydrology, 509:573-587.

McMillan, H., Freer, J., Pappenberger, F., Krueger, T., and Clark, M. (2010). 
Impacts of uncertain river flow data on rainfall-runoff model calibration and discharge predictions. Hydrological Processes, 24(10):1270-1284.

McMillan, H., Krueger, T., and Freer, J. (2012). Benchmarking observational uncertainties for hydrology: rainfall, river discharge and water quality. Hydrological Processes, 26(26):4078-4111.

Morlot, T., Perret, C., Favre, A.-C., and Jalbert, J. (2014). Dynamic rating curve assessment for hydrometric stations and computation of the associated uncertainties: Quality and station management indicators. Journal of Hydrology, 517:173-186.

Nash, J. E. and Sutcliffe, J. V. (1970). River flow forecasting through conceptual models part I A discussion of principles. Journal of Hydrology, $10(3): 282-290$.

Pelletier, P. M. (1988). Uncertainties in the single determination of river discharge: a literature review. Canadian Journal of Civil Engineering, $15(5): 834-850$.

Petersen-Øverleir, A. and Reitan, T. (2009). Accounting for rating curve imprecision in flood frequency analysis using likelihood-based methods. Journal of Hydrology, 366(1-4):89-100.

Rantz, S. et al. (1982). Measurement and computation of stream flow. volume 1: Measurement of stage and discharge; volume 2: Computation of discharge. US Geological Survey water-supply paper, 2175:631.

Sauer, V. B. and Meyer, R. W. (1992). Determination of error in individual discharge measurements. 
Shrestha, R. R. and Simonovic, S. P. (2010). Fuzzy set theory based methodology for the analysis of measurement uncertainties in river discharge and stage. Canadian Journal of Civil Engineering, 37(3):429-440.

WMO (2010). Manual on stream gauging - Vol I. World Meteorological Organization, Geneva. 


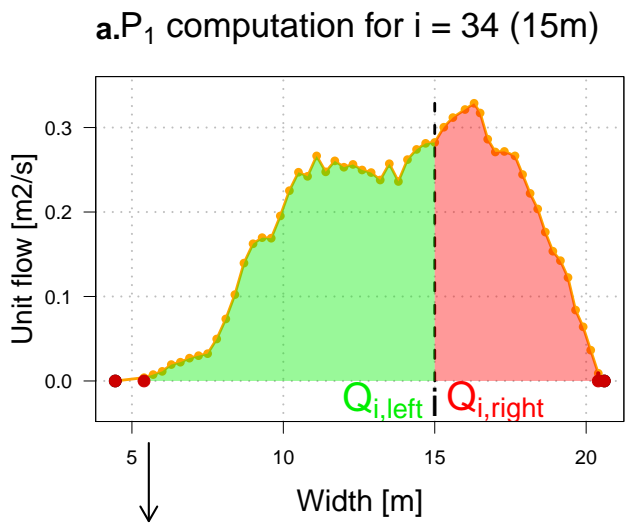

c. Probability $P_{1}$

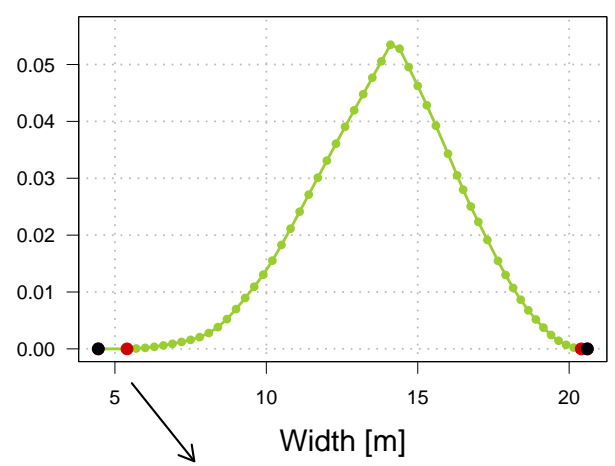

b. $P_{2}$ computation for $i=34(15 \mathrm{~m})$

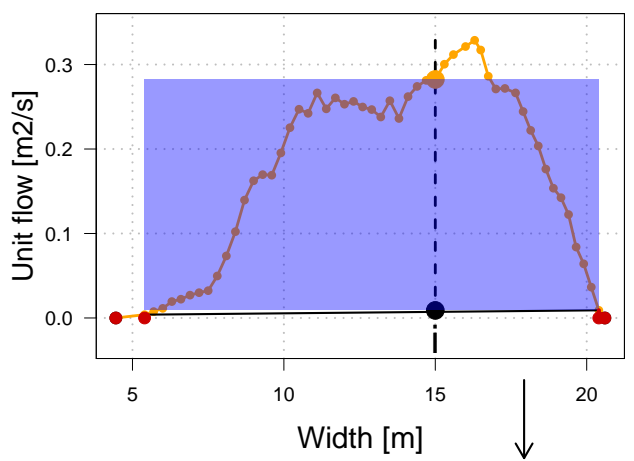

d. $\quad$ Probability $\mathrm{P}_{2}$

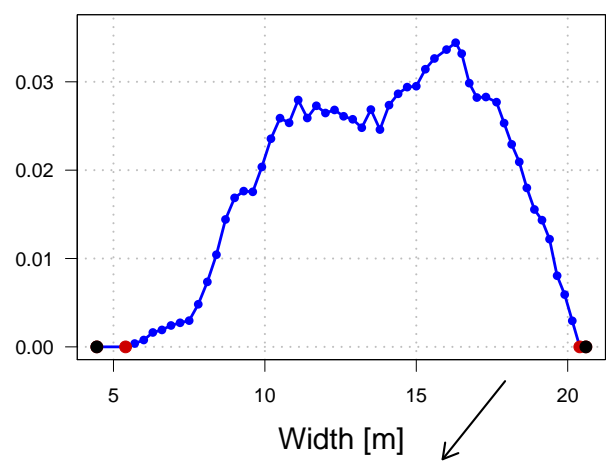

e.

Final probability $\mathrm{P}=\mathrm{P}_{1}+\mathrm{P}_{2} / 2$

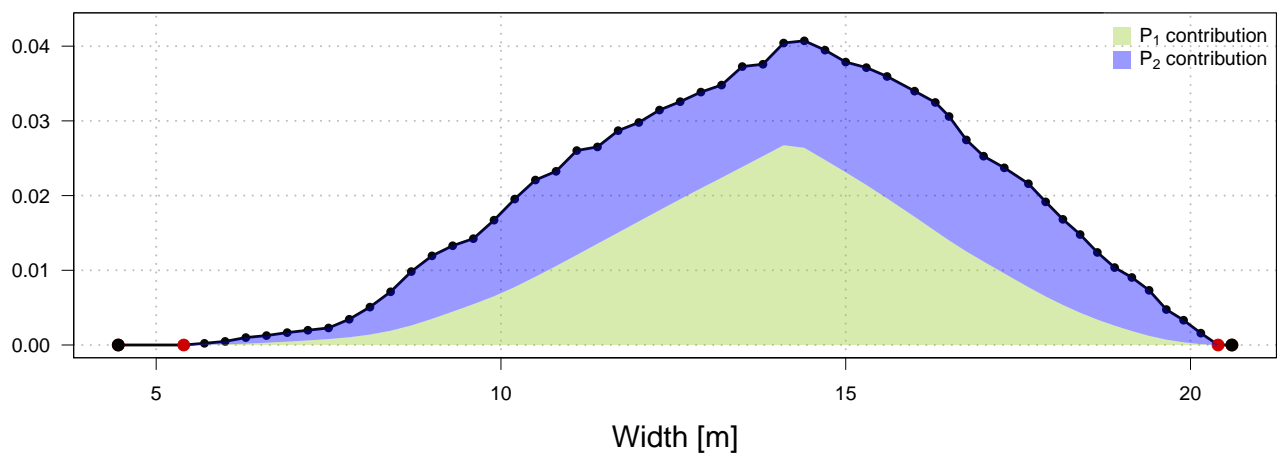

Figure 1: Probability computation procedure for the Buech river gauging at Serres. The black vertical dashed line represents vertical $i$. Red points correspond to verticals already sampled. (a): $P_{1}$ computation. In green, partial flow to the left and in red, partial flow to the right. $P_{1, i}$ is proportional to the minimum value between $Q_{i, \text { right }}$ and $Q_{i, l e f t}$; (b): $P_{2}$ computation. Oblique solid line is the interpolation between the closest sampled verticals of vertical $i$. The area in blue is proportional to $P_{2, i} ;(\mathrm{c}): P_{1}$ probability distribution; (d): $P_{2}$ probability distribution; (e): Final probability distribution. 


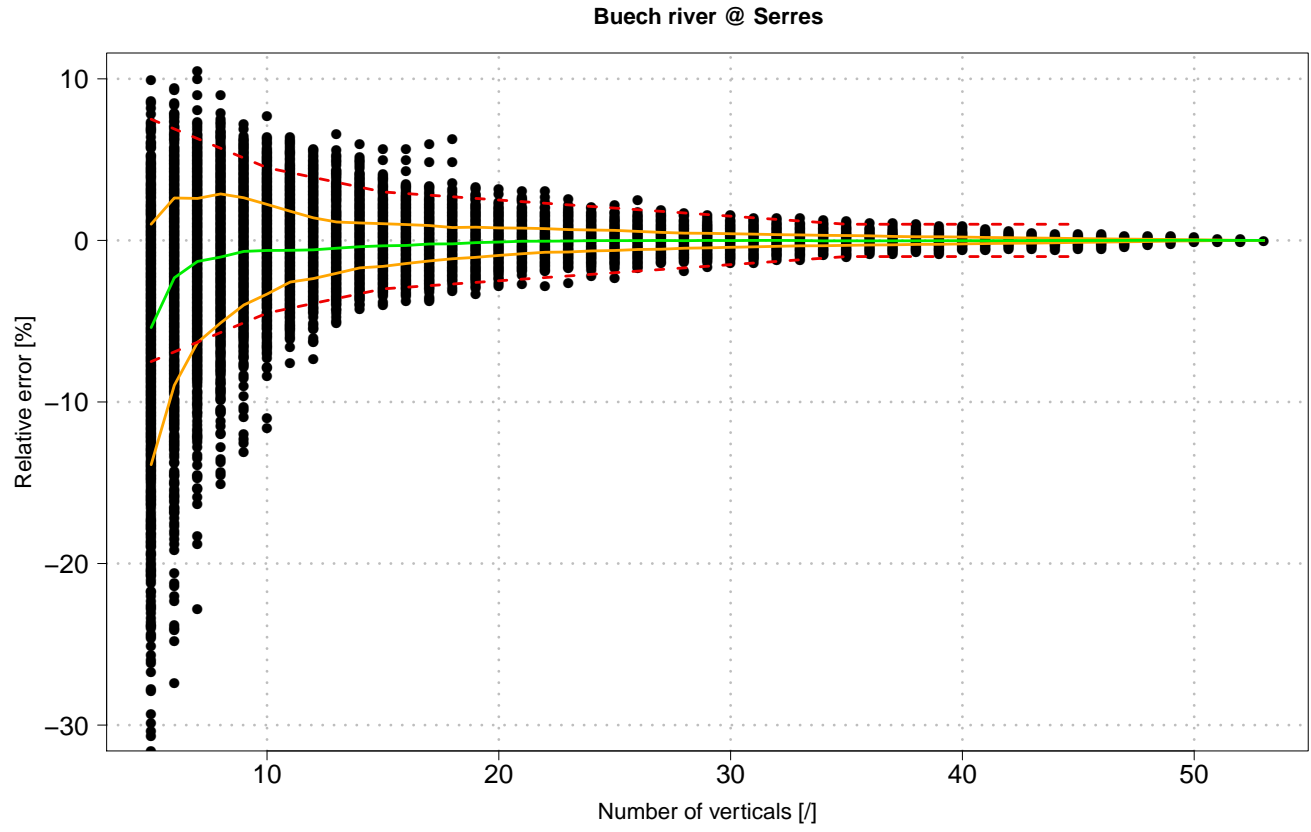

Figure 2: Relative error depending on the number of verticals for the Buech river gauging at Serres. Red dashed line represent ISO 748 estimation of $u_{m}$ while orange solid lines are $15 \%$ and $85 \%$ empirical percentiles. The green solid lines is the median. 


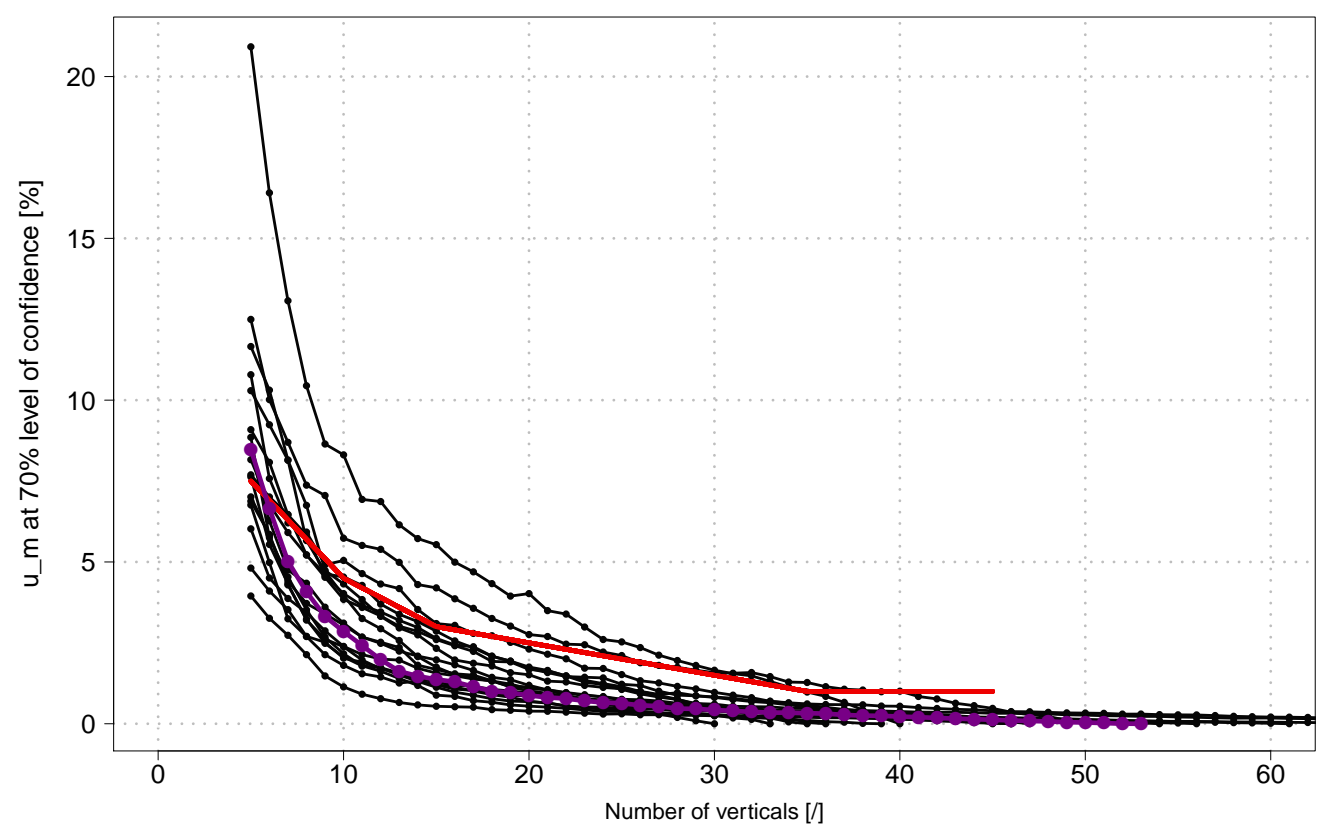

Figure 3: $u_{m}$ estimation for each reference stream-gauging depending on the number of verticals according to the introduced subsampling method. The Buech at Serres gauging station is plotted in purple. The red line represents values given in ISO 748 . 
Author-produced version of the article published in Journal of Hydrology (2016), $n^{\circ} 533$, p. $128-140$

The original publication is available at http://www.sciencedirect.com/ doi : 10.1016/j.jhydrol.2015.11.048

(c) This manuscript version is made available under the CC-BY-NC-ND 4.0 license http://creativecommons.org/licenses/by-nc-nd/4.0/

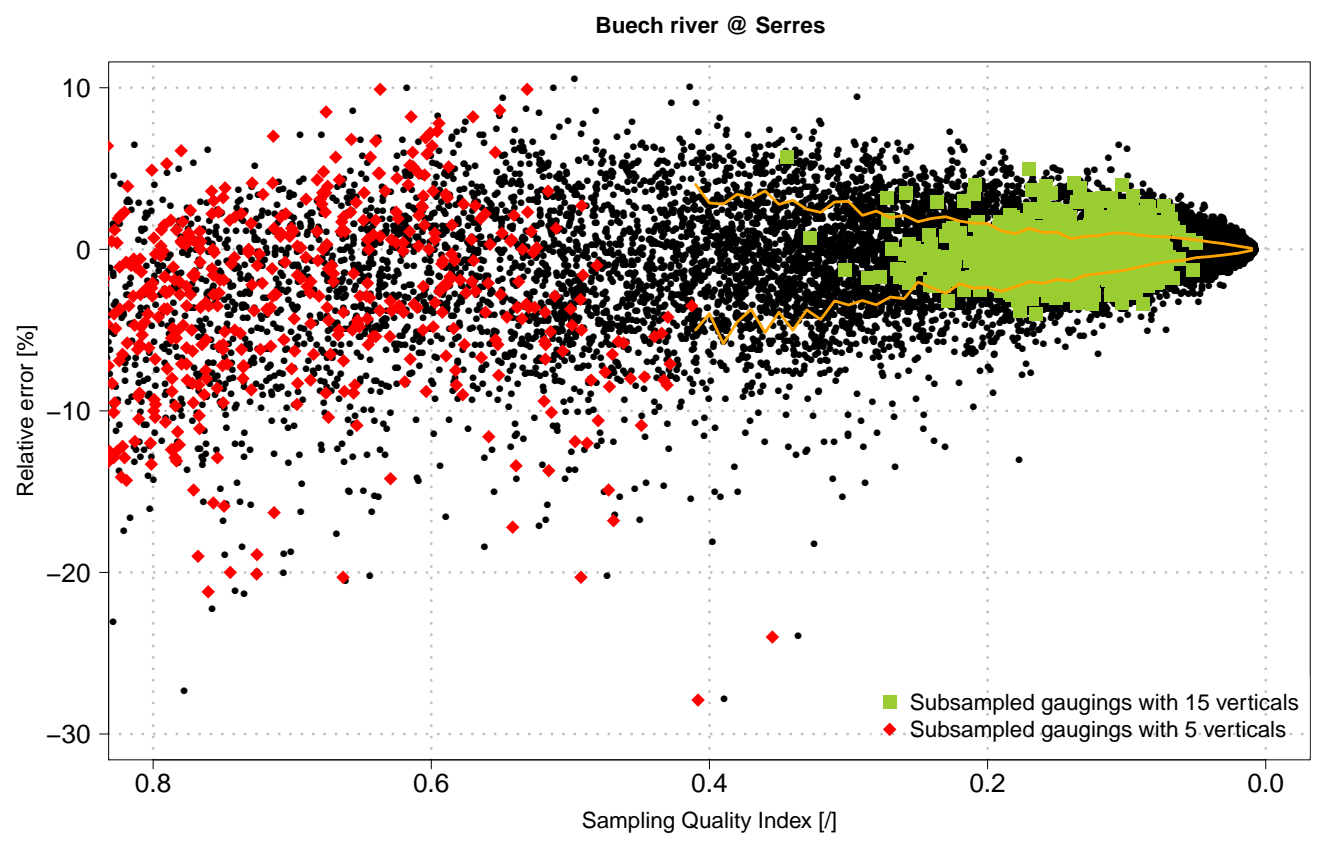

Figure 4: Relative error depending on sampling quality index and computation of $u_{m}$ for the Buech river at Serres. Black dots represent all the subsampled gaugings. Red diamonds (respectively green squares) show all 1000 subsampled stream-gaugings with 5 (respectively 15) verticals. Note that $x$-axis is decreasing. 
a.

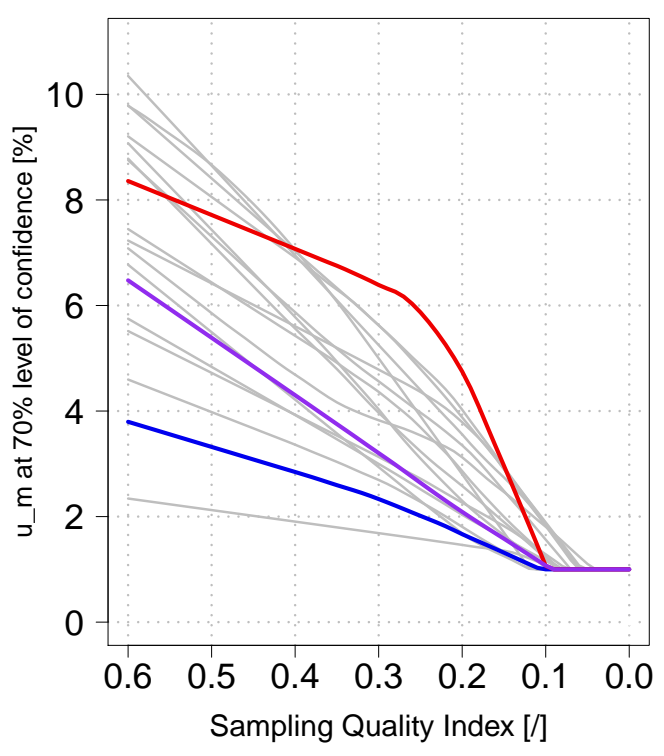

b. Severaissse @ Villar Loubiere

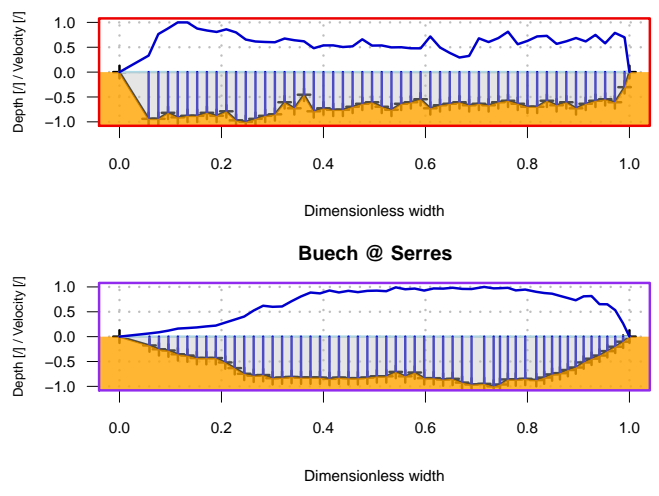

Rhone@ Tricastin

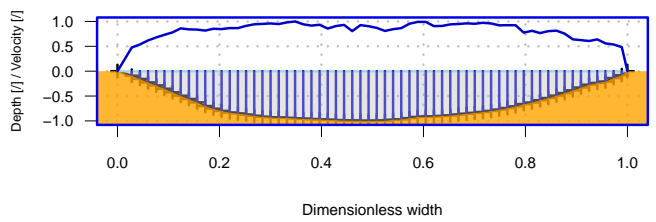

Figure 5: (a): $u_{m}$ estimation for each reference stream-gauging depending on the sampling quality index. Séveraisse @ Villar stream-gauging is plotted in red, Buech @ Serres streamgauging in purple and Rhône @ Tricastin stream-gauging in blue. Note that $x$-axis is decreasing. (b): Lateral velocity distributions and bathymetric dimensionless profiles of the three stream-gauging examples. 


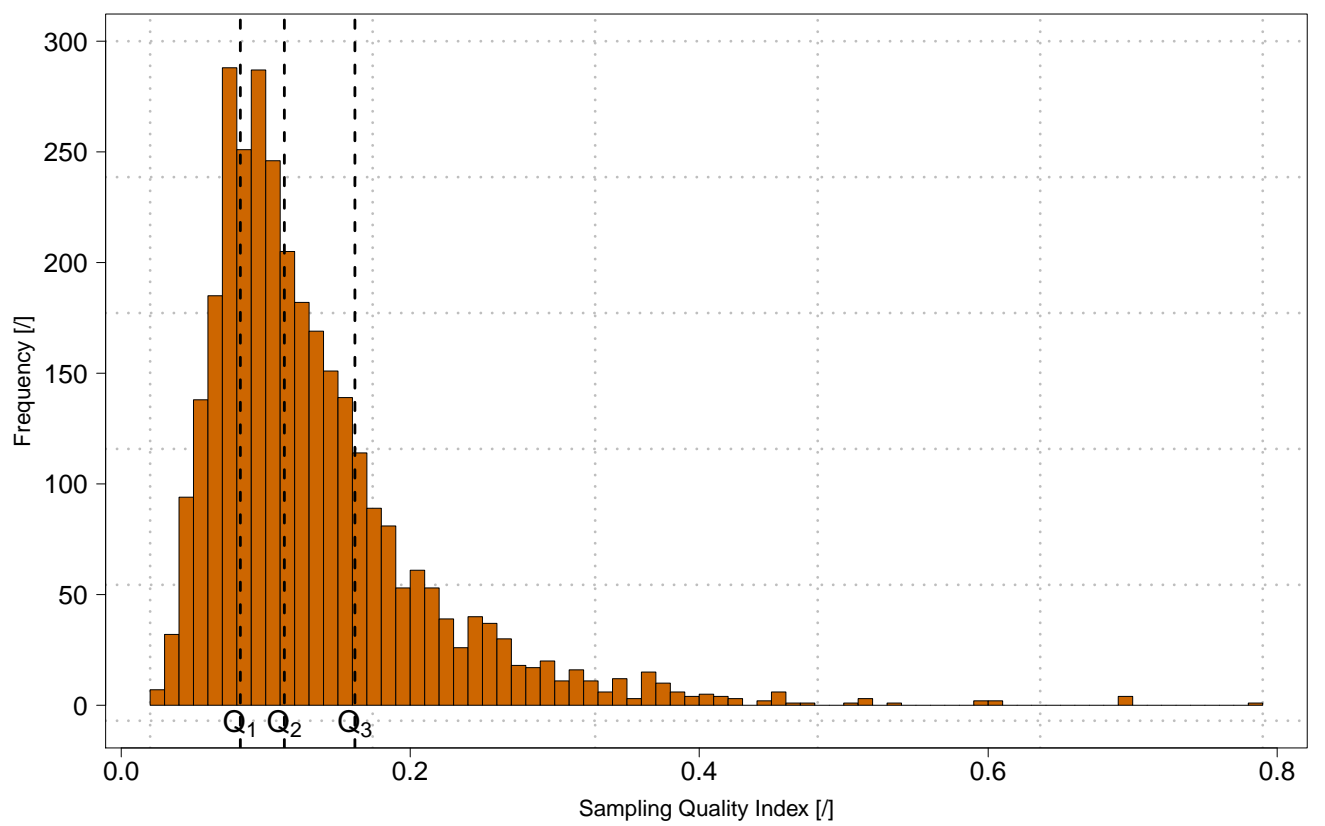

Figure 6: Distribution of sampling quality index values computed over the whole EDFDTG database (3185 stream-gaugings). $Q_{1}, Q_{2}$ and $Q_{3}$ denote the first, second and third quartiles, respectively, and are represented by the vertical dashed lines. 
ISO

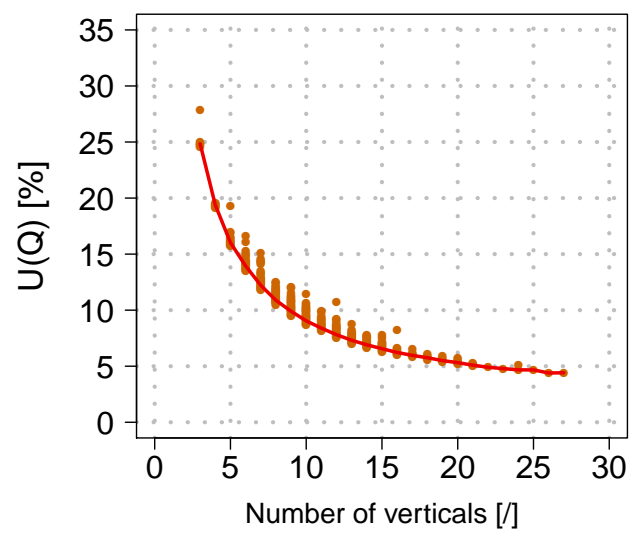

Q+

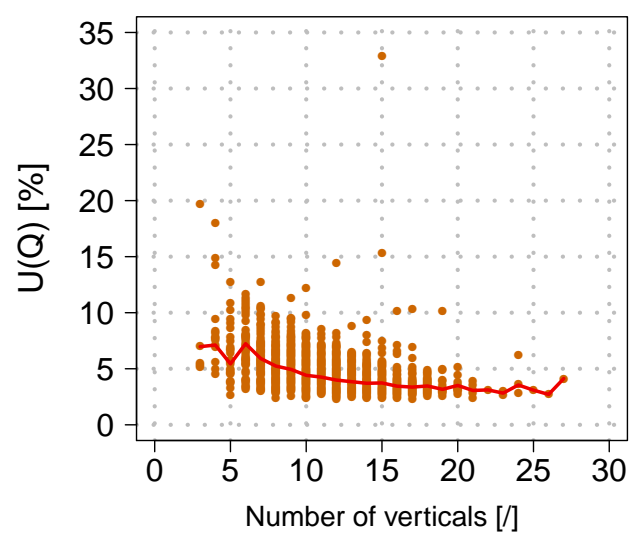

IVE

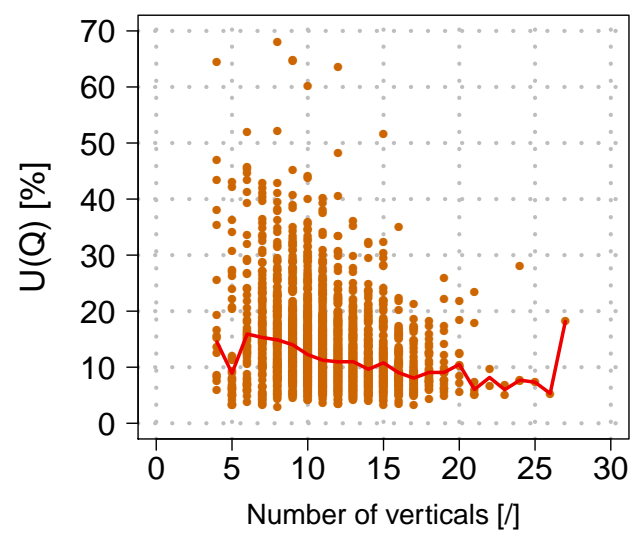

Flaure

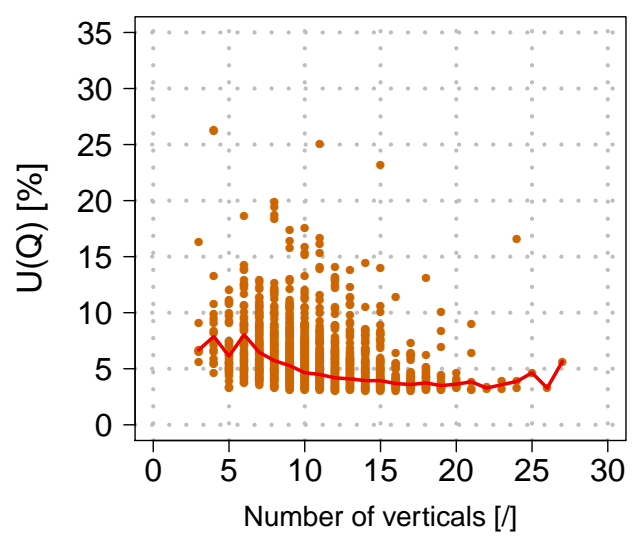

Figure 7: Uncertainties depending on the number of verticals (at $95 \%$ confidence level) computed with ISO, $Q+, I V E$ and FlaURE methods using EDF-DTG dataset. The solid red line represents the median. 
ISO

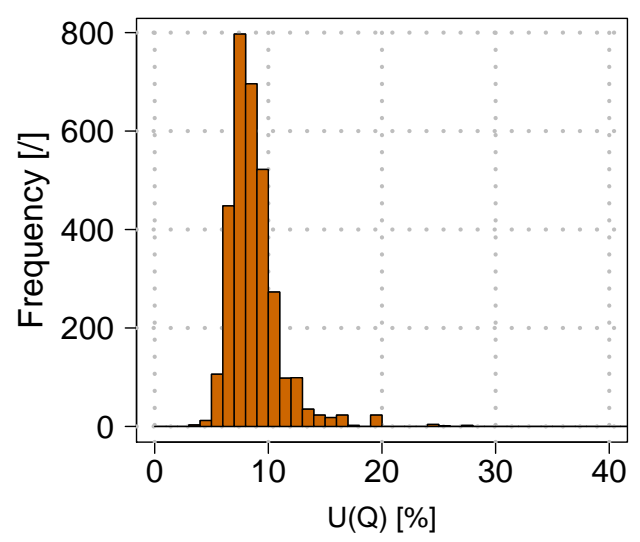

Q+

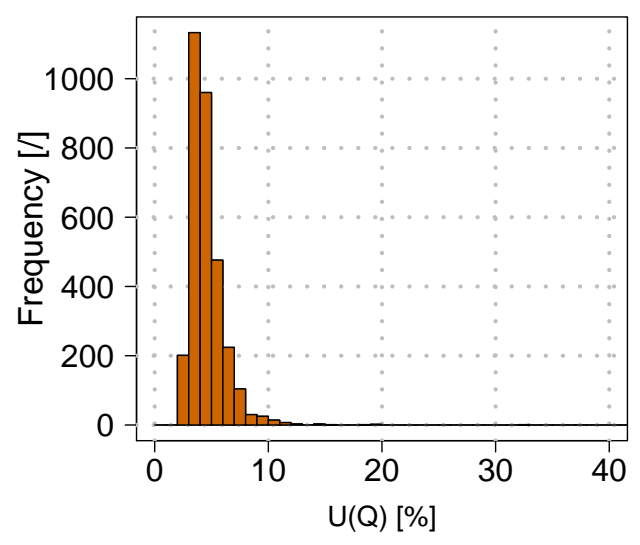

IVE

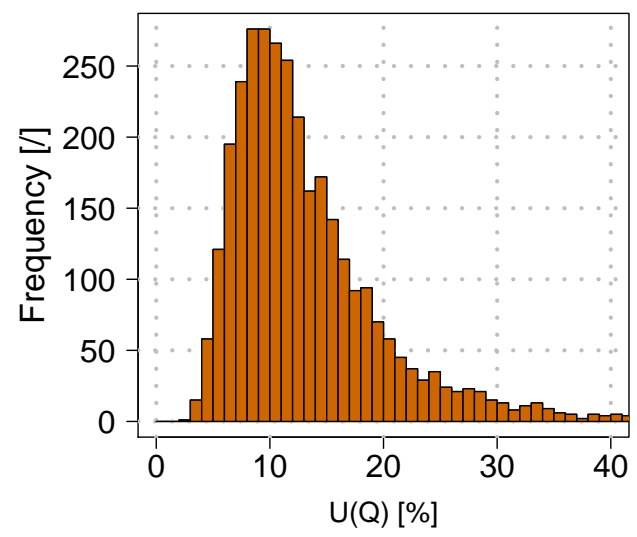

Flaure

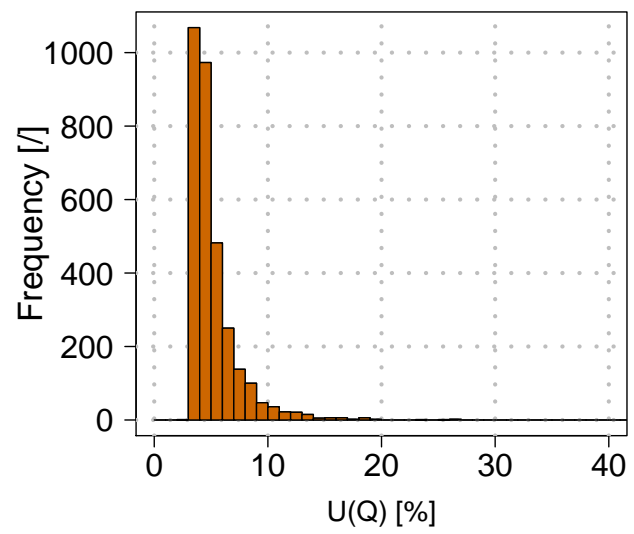

Figure 8: Distribution of uncertainties computed with ISO, $Q+, I V E$ and FlaURE methods using EDF-DTG dataset (at 95\% confidence level). 
a.

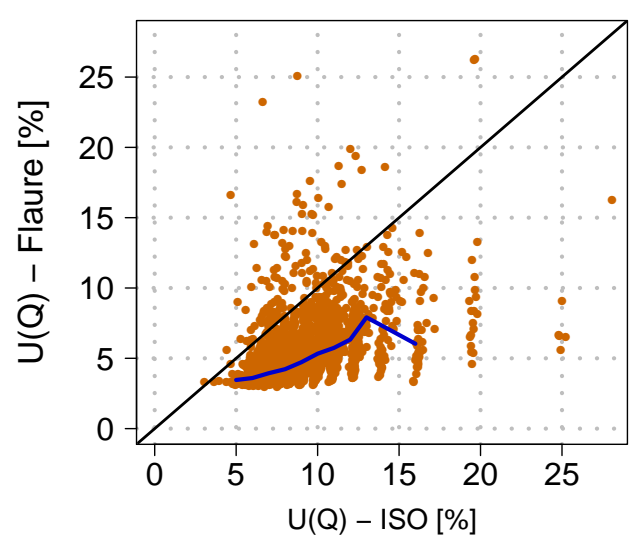

c.

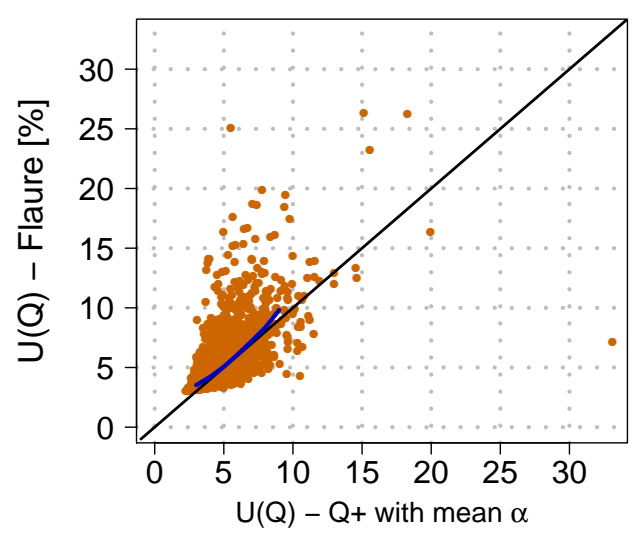

b.

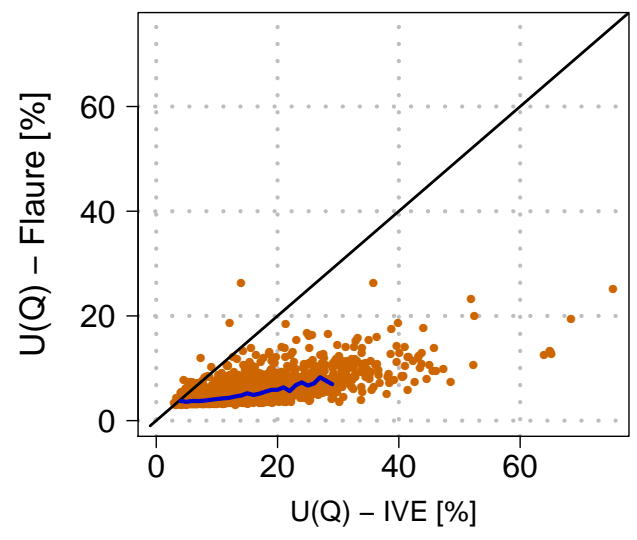

d.

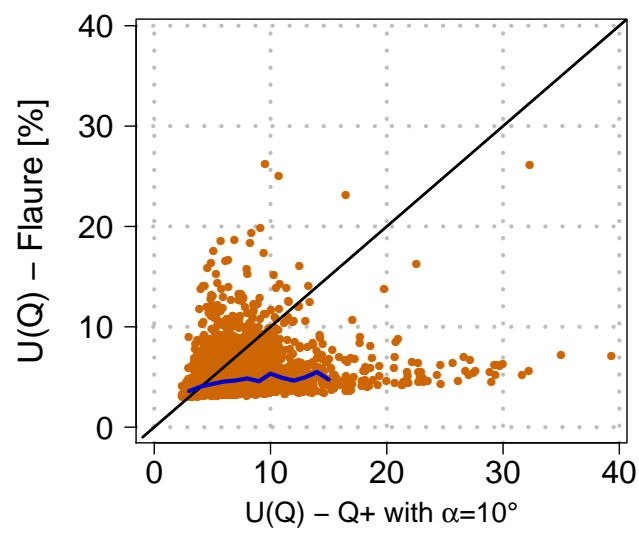

Figure 9: Comparison of the FlaURE approach with other methods in terms of uncertainties (at 95\% confidence level). Blue line is the median. Oblique black line is the first bisector. 

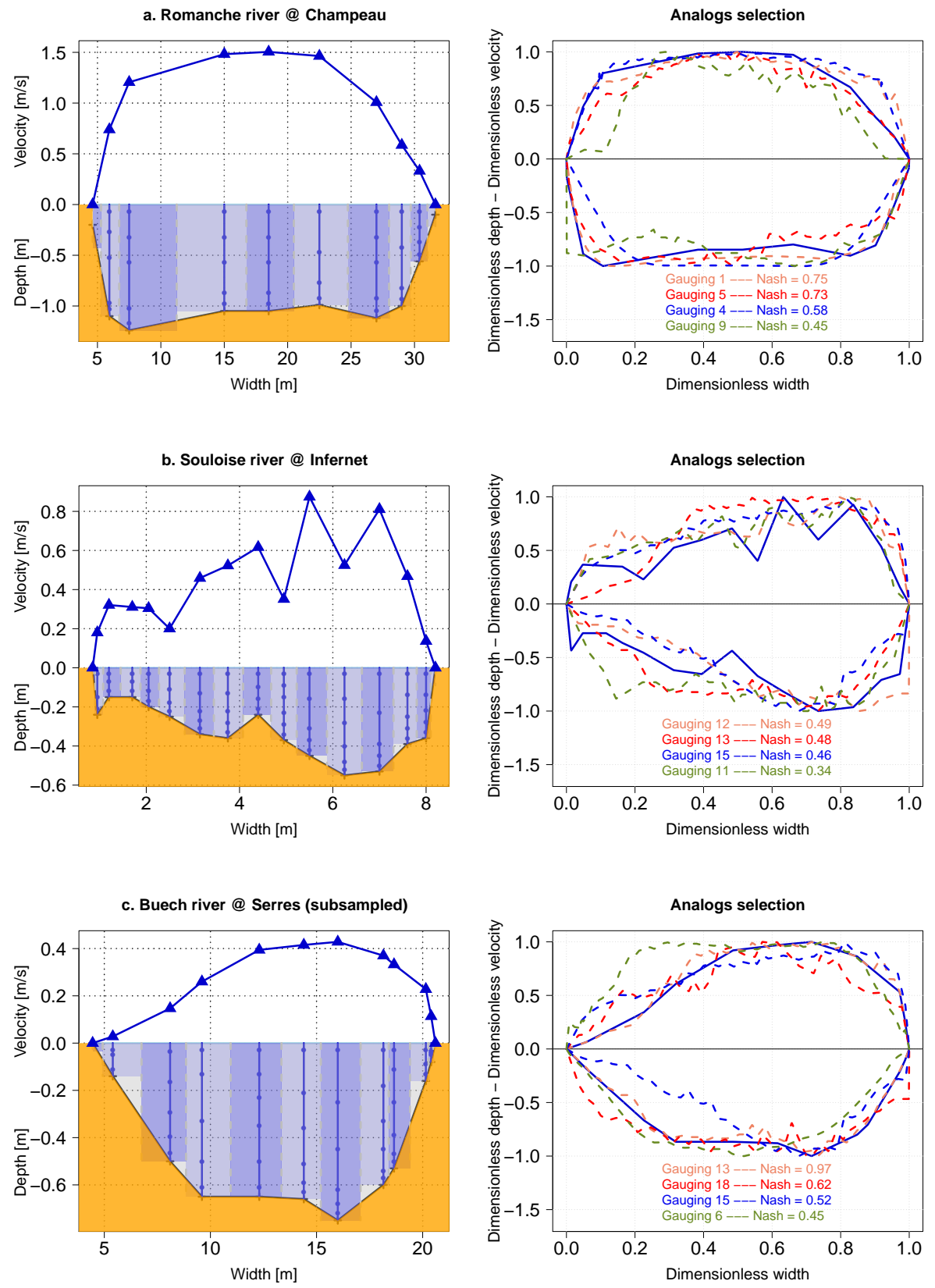

Figure 10: Illustration of the analogs selection for the three test cases. a. The Romanche river stream-gauging at Chapeau station (case 1). b. The Souloise river stream-gauging at Infernet station (case 2). c. Subsampled stream-gauging from Buech river at Serres station (case 3). For each case, scores printyged on right hand graphs correspond to Nash values of the four best analogs. Gauging numbers refer to Table 1. 
Table 1: Characteristics of the reference stream-gaugings used for this study. $m^{*}$ is the number of verticals. $M C M^{*}$ indicates mechanical current-meter measurement.

\begin{tabular}{|c|c|c|c|c|c|c|c|c|}
\hline Number & Location & River & Type & Date & $\begin{array}{c}\text { Width } \\
\text { [m] }\end{array}$ & $\begin{array}{c}\text { Depth } \\
{[\mathrm{m}]}\end{array}$ & $\begin{array}{c}\text { Discharge } \\
{\left[\mathrm{m}^{3} / \mathrm{s}\right]}\end{array}$ & $m^{*}$ \\
\hline 1 & Allassac & Vézère & $\mathrm{ADCP}$ & 20090205 & 36.7 & 2.90 & 29.9 & 54 \\
\hline 2 & Chavanay & Rhône & $\mathrm{ADCP}$ & 20081218 & 342 & 15.4 & 1010 & 83 \\
\hline 3 & Chavanay & Rhône & $\mathrm{ADCP}$ & 20140806 & 343 & 14.1 & 1332 & 79 \\
\hline 4 & Miramont Comminges & Gentille & $\mathrm{ADCP}$ & 20110913 & 17.2 & 3.43 & 15.8 & 56 \\
\hline 5 & Rocherousse & Durance & $\mathrm{ADCP}$ & 20131009 & 23.8 & 0.91 & 11.6 & 46 \\
\hline 6 & Tricastin & Rhône & $\mathrm{ADCP}$ & 20130918 & 152 & 14.1 & 1009 & 80 \\
\hline 7 & Tricastin & Rhône & $\mathrm{ADCP}$ & 20140304 & 146 & 13.3 & 1664 & 61 \\
\hline 8 & Les Chambons & Buech & $\mathrm{MCM}^{*}$ & 20140722 & 18.1 & 0.85 & 2.98 & 47 \\
\hline 9 & Nant 1 & Durzon & $\mathrm{MCM}^{*}$ & 20131016 & 5.70 & 0.41 & 1.05 & 35 \\
\hline 10 & Nant 2 & Durzon & $\mathrm{MCM}^{*}$ & 20131017 & 5.90 & 0.52 & 0.93 & 31 \\
\hline 11 & Pont-En-Royans & Vernaison & $\mathrm{MCM}^{*}$ & 20010127 & 10.4 & 0.26 & 0.81 & 34 \\
\hline 12 & Sassenage & Furon & $\mathrm{MCM}^{*}$ & 20130710 & 6.80 & 0.67 & 0.18 & 35 \\
\hline 13 & Serres & Buech & $\mathrm{MCM}^{*}$ & 20140722 & 16.2 & 0.79 & 2.81 & 53 \\
\hline 14 & Seuil de Premont & Arc & $\mathrm{MCM}^{*}$ & 20140723 & 3.50 & 0.81 & 1.80 & 46 \\
\hline 15 & Seuil de Premont Canal & Arc & $\mathrm{MCM}^{*}$ & 20140723 & 9.00 & 0.86 & 1.75 & 47 \\
\hline 16 & St Georges de Luzencon & Cernon & $\mathrm{MCM}^{*}$ & 20131016 & 13.8 & 0.63 & 0.79 & 40 \\
\hline 17 & Villar Loubière & Séveraisse & $\mathrm{MCM}^{*}$ & 20100128 & 10.5 & 0.33 & 1.34 & 50 \\
\hline \multirow[t]{3}{*}{18} & Voiron & Morge & $\mathrm{MCM}^{*}$ & 20130710 & 7.00 & 0.45 & 0.66 & 47 \\
\hline & & & & Minimum & 3.50 & 0.33 & 0.18 & 31 \\
\hline & & & & Maximum & 343 & 15.4 & 1664 & 83 \\
\hline
\end{tabular}


Table 2: Statistical characteristics of the 3185 stream-gaugings from EDF-DTG database.

\begin{tabular}{rlllll}
\hline & $\begin{array}{l}\text { Discharge } \\
{\left[\mathrm{m}^{3} / \mathrm{s}\right]}\end{array}$ & $\begin{array}{l}\text { Width } \\
{[\mathrm{m}]}\end{array}$ & $\begin{array}{l}\text { Depth } \\
{[\mathrm{m}]}\end{array}$ & $\begin{array}{l}\text { Mean velocity } \\
{[\mathrm{m} / \mathrm{s}]}\end{array}$ & Number of verticals \\
\hline Minimum & 0.01 & 0.49 & 0.10 & 0.03 & 3 \\
First quartile & 0.60 & 6.60 & 0.40 & 0.27 & 10 \\
Median & 1.43 & 10.1 & 0.55 & 0.43 & 11 \\
Mean & 7.98 & 13.2 & 0.65 & 0.52 & 11 \\
Third quartile & 3.55 & 16.6 & 0.75 & 0.63 & 13 \\
Maximum & 863 & 90.3 & 7.40 & 3.60 & 32 \\
\hline
\end{tabular}

Table 3: Results of the uncertainty analysis of the stream-gauging test cases. $m^{*}$ is the number of verticals.

\begin{tabular}{rlllllllll}
\hline Name & Width & Depth & Discharge & $\boldsymbol{m}^{*}$ & $\boldsymbol{I S O}$ & $\boldsymbol{I V E}$ & $\alpha$ & $\boldsymbol{Q}+$ & \multicolumn{2}{c}{ Flaure } \\
& {$[\mathrm{m}]$} & {$[\mathrm{m}]$} & {$\left[\mathrm{m}^{3} / \mathrm{s}\right]$} & & $\mathrm{U}(\mathrm{Q})[\%]$ & $\mathrm{U}(\mathrm{Q})[\%]$ & {$\left[{ }^{\circ}\right]$} & $\mathrm{U}(\mathrm{Q})[\%]$ & $\mathrm{U}(\mathrm{Q})[\%]$ \\
\hline Romanche@Champeau & 27.0 & 1.24 & 33.7 & 8 & 10.7 & 13.8 & 3 & 4.6 & 4.0 \\
Souloise@Infernet & 7.35 & 0.55 & 1.34 & 14 & 7.0 & 32 & 8 & 4.0 & 10.0 \\
Buech@Serres & 16.2 & 0.75 & 2.75 & 10 & 9.0 & 11.3 & 3 & 4.2 & 5.2 \\
\hline
\end{tabular}

